\title{
Hydrogen-based Energy Storage (IEA-HIA Task 32)
}

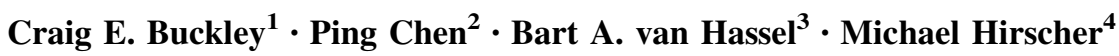

Received: 18 January 2016/Accepted: 20 January 2016/Published online: 11 February 2016

(c) The Author(s) 2016. This article is published with open access at Springerlink.com

Energy storage is considered as one of the most challenging aspects for achieving an economy based on renewable energy sources. During the past 10-15 years hydrogen has gained importance as an energy carrier. Hydrogen storage is the key for the wide spread use of renewable energy into many applications, such as fuel for fuel-cell vehicles and portable devices or as energy storage in general for stationary applications. The first fuel-cell vehicles delivered to customers by Hyundai and Toyota have been equipped with highpressure vessels (70 MPa) requiring expensive carbon fibers. A reduction in the storage pressure would reduce the cost of the vessel and the high compression cost at the refueling station, while improving system availability. Hydrogen storage as liquid hydrogen at $20 \mathrm{~K}$ involves a number of challenges (e.g. dormancy and cost) and is not considered for most applications. Hydrogen storage in solid materials or as liquid hydrogen carriers constitutes an alternative, which possesses the potential to surpass the storage densities of compressed hydrogen. Important driving forces for further strong research activities on hydrogen storage in solid or liquid compounds are the potential high volumetric density, storage at lower pressure that can be close to ambient conditions and

Michael Hirscher

hirscher@mf.mpg.de

1 Department of Physics, Astronomy, and Medical Radiation Sciences, Curtin University, GPO Box U1987, Perth, WA 6845, Australia

2 Dalian Institute of Chemical Physics, Chinese Academy of Sciences, Dalian 116023, China

3 United Technologies Research Center, 411 Silver Lane, East Hartford, CT 06108, USA

4 Max Planck Institute for Intelligent Systems, Heisenbergstrasse 3, 70569 Stuttgart, Germany significantly improved safety. Beside possible applications in vehicles, worldwide activities increased significantly for hydrogen used for energy storage, owing to the change from fossil to "green" energy sources such as wind and solar power. For these stationary applications, hydrogen storage in solids or liquids is an attractive concept. Furthermore, metal hydrides are important constituents in metal hydride batteries and also possible as electrolytes in Li-ion batteries. Additionally, concentrated solar thermal plants can provide enough energy in countries with long intensive sunshine, e.g., south Spain, Australia or Nevada, USA. The key for such power plants is adequate heat storage during the day to run the thermal power plant continuously for $24 \mathrm{~h}$. Presently, the pilot plants use molten salt as heat storage medium; however, the development of high-temperature metal hydrides may open a new and more cost-effective solution for heat storage.

The International Energy Agency (IEA) in its Hydrogen Implementation Agreement (HIA) conducts the core R\&D work in Tasks by Member Experts. Task 32 "Hydrogen-based Energy Storage" addresses solutions for energy storage based on hydrogen. Task 32 is the largest international collaboration in this field involving over 50 experts from 18 countries. Currently, the task consists of six working groups:

- Porous materials

- Magnesium-based hydrogen and energy storage materials

- Complex and liquid hydrides

- Electrochemical storage of energy

- Heat storage-concentrated solar thermal using metal hydrides

- Hydrogen storage systems for mobile applications

In this topical collection on "Hydrogen-based Energy Storage" the Task 32 Experts present the current status of research and future outlook in 20 invited papers. 
Acknowledgments Open access funding provided by Max Planck Society (Max Planck Institute for Intelligent Systems).

Open Access This article is distributed under the terms of the Creative Commons Attribution 4.0 International License (http://crea tivecommons.org/licenses/by/4.0/), which permits unrestricted use, distribution, and reproduction in any medium, provided you give appropriate credit to the original author(s) and the source, provide a link to the Creative Commons license, and indicate if changes were made. 